\title{
Laboreal
}

Volume 9 No$^{\circ} 2$ | 2013

Varia

\section{Presentación esquemática del concepto de representación en ergonomía}

Apresentação esquemática do conceito de representação em ergonomia Présentation schématique du concept de représentation en ergonomie.

Schematic outline of the representation concept used in ergonomics

\section{Catherine Teiger}

\section{(2) OpenEdition}

Journals

Edición electrónica

URL: http://journals.openedition.org/laboreal/5860

DOI: $10.4000 /$ laboreal. 5860

ISSN: 1646-5237

\section{Editor}

Universidade do Porto

\section{Referencia electrónica}

Catherine Teiger, «Presentación esquemática del concepto de representación en ergonomía », Laboreal [En línea], Volume 9 N² | 2013, Publicado el 01 diciembre 2013, consultado el 24 septiembre 2020. URL : http://journals.openedition.org/laboreal/5860 ; DOI : https://doi.org/10.4000/laboreal. 5860

Este documento fue generado automáticamente el 24 septiembre 2020.

Laboreal está licenciado com uma Licença Creative Commons - Atribuição-NãoComercial 4.0 Internacional. 


\title{
Presentación esquemática del concepto de representación en ergonomía
}

\author{
Apresentação esquemática do conceito de representação em ergonomia \\ Présentation schématique du concept de représentation en ergonomie. \\ Schematic outline of the representation concept used in ergonomics
}

Catherine Teiger

\section{REFERENCIA}

Artículo original : Teiger, C. (1990). Présentation schématique du concept de réprésentation en ergonomie. In M. Dadoy, Cl. Henry, B. Hillau, G. De Terssac, J.-F. Troussier, A. Weill-Fassina. Les analyses du travail enjeux et formes (199-205). Paris CEREQ (Centre d'Études et de Reherches sur les Qualifications). Collection des Études $\mathrm{n}^{\circ} 54$.

\section{Origen y papel del concepto de representación}

1 El concepto de representación es, desde hace veinte años, probablemente uno de los más expandidos y de los más productivos en psicología del trabajo y en la ergonomía. Aunque ciertos autores prefieran el término "modelo mental" [BAINBRIDGE (1969] la idea principal que se debe tener en cuenta es que "un proceso de procesamiento no funciona directamente sobre lo real sino que se adapta a esa representación" [BISSERET (1970), (1971)].

2 Sin embargo, el término "representación" puede presentar confusiones porque expresa a la vez "el modelo interiorizado de la realidad que asegura la orientación de la acción" y también "el proceso por el cual la persona constituye ese modelo". 
El papel de la representación en la orientación de la acción es esencial : "mediante la representación el operador constituye su información sobre el objeto. Esta permite al operador organizar mentalmente la solución, calcular sus acciones a partir de ese modelo interiorizado del sistema técnico. Esa representación va a permitir una simulación mental que será un factor esencial de la planificación de la acción" [LEPLAT (1985)].

4 El origen del concepto de representación se remonta a la filosofía griega. Para Aristóteles "la idea de objeto es su reflejo ideal". A finales del siglo XIX la psicología general con el asociacionismo y la escuela de Würzburg busca "identificar la naturaleza de la imagen mental". Esas teorías se mantuvieron adormecidas durante el momento de gloria del behaviorismo, que solo se interesa por las entradas y salidas del operador humano (esquema estímulo - respuesta) y se niega a preocuparse por lo que pasa en la "caja negra" del cerebro.

5 Precisamente como reacción contra esta escuela, durante los años 60, la noción de "imagen mental" se convierte en objeto de una recuperación del interés por parte de dos grandes corrientes de investigación :

- por un lado la psicología genética, con PIAGET [PIAGET et al. (1966)] para quien "la imagen es una limitación activa e interiorizada de la percepción" que aparece bastante tarde en la ontogénesis (durante dos años, en forma de simples imágenes "reproductoras", después, durante siete - ocho años en forma de imágenes "anticipativas"). La imagen todavía se mantiene en segundo plano si la comparamos con las operaciones mentales efectuadas por el sujeto ;

- por otro lado la escuela rusa de psicología y de psicofisiología, en particular la de la psicología del trabajo con LOMOV y sobre todo OSHANIN, que crea el neologismo de imagen "operativa" al cual volveremos más adelante.

6 En estos último años las investigaciones sobre la imagen mental y sobre las representaciones (y nociones cercanas) sufrirán un desarrollo considerable debido a (es una banalidad recordarlo) la introducción de los dispositivos automatizados e informatizados que suprimen el contacto directo del operador con el objeto de trabajo y le obligan a actuar a través de intermediarios La representación del sistema desempeña un papel, más que nunca, preponderante. Las investigaciones son demasiado numerosas para ser citadas aquí. Se darán algunos ejemplos de entre los más significativos a propósito de las cuestiones planteadas por su construcción, las condiciones de acceso, su reestructuración en el transcurso de la acción, errores, etc.

\section{De la "imagen operativa" a la "representación funcional"}

7 A OSHANIN le gustaba contar que la idea de una funcionalidad de la imagen mental se le había ocurrido al constatar que los caminos tomados por los transeúntes para atravesar una plaza de Moscú cubierta de nieve no tenían nada que ver con los trayectos geométricos diseñados por el arquitecto. Numerosas experiencias de laboratorio sobre la teleconducción, entre otras, y estudios sobre el trabajo, realizados principalmente con los dispositivos de control de centrales térmicas, le hicieron constatar que los operadores utilizan únicamente cierta información ofrecida por el 
dispositivo. Más aún, el esquema tecnológico completo y la instalación, les molesta más que ayudarlos.

8 Utilizan aquello que OSHANIN denomina inicialmente esquema "psicológico", lo cual pone en evidencia solo las relaciones entre los elementos del sistema (circuito de la central, por ejemplo) que son esenciales para ellos para ejecutar el trabajo. En la práctica, este esquema, a pesar de ser parcialmente incorrecto, permite a quienes lo utilizan, tener un éxito mayor y más rápido que quienes utilizan el esquema tecnológico del ingeniero. Basándose en numerosas observaciones de este tipo OSHANIN acuñó la idea "de imagen operativa" en el sentido en que ésta permite actuar :

"La acción sobre el objeto puede definirse como un proceso en el que la información sobre los estados sucesivos del objeto se transforma en acciones finalizadas sobre este objeto. Esta transformación tiene lugar en la secuencia de una confrontación procedente del objeto con la que el sujeto ya posee, por ejemplo la información sobre la forma o la estructura del objeto, o su estado deseado, el algoritmo de su funcionamiento como sistema dinámico, etc. (...) Esta información preexistente con la cual se confronta la información "exteroceptiva", aparece con mucha frecuencia organizada en una imagen operativa caracterizada ante todo por su organización estructural" [OSHANIN (1969)]. Lo que implica que "no podemos creer en la idea de una imagen universal" [OSHANIN (1977)]. Una afirmación con consecuencias teóricas y prácticas de peso, especialmente importantes para la ergonomía.

Figura 1. Variante "psicológica"

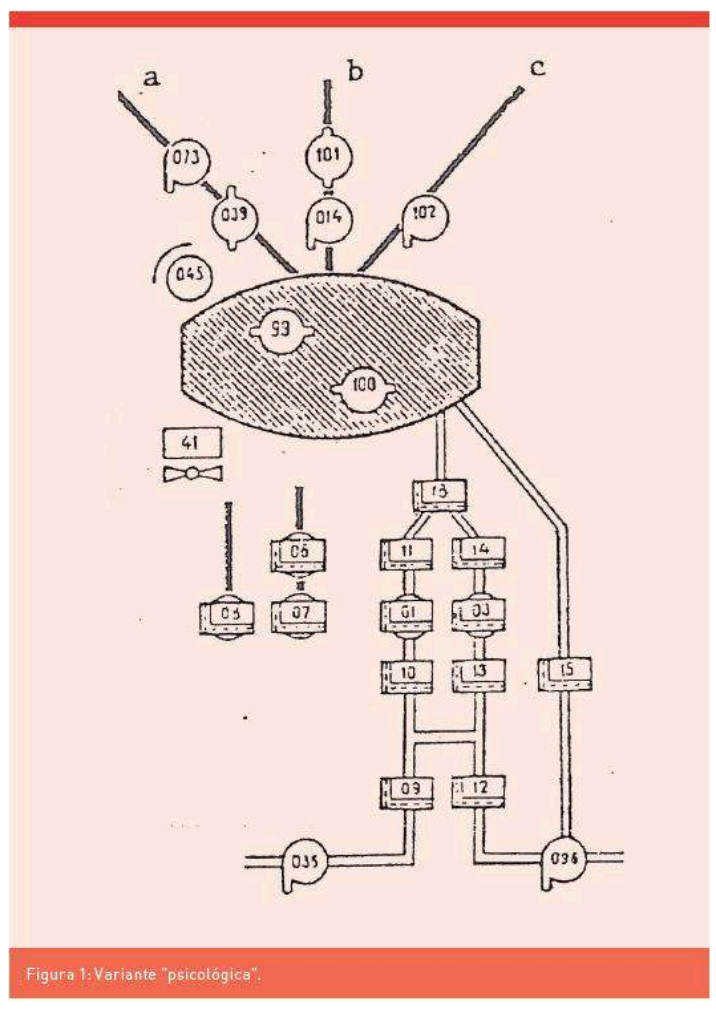




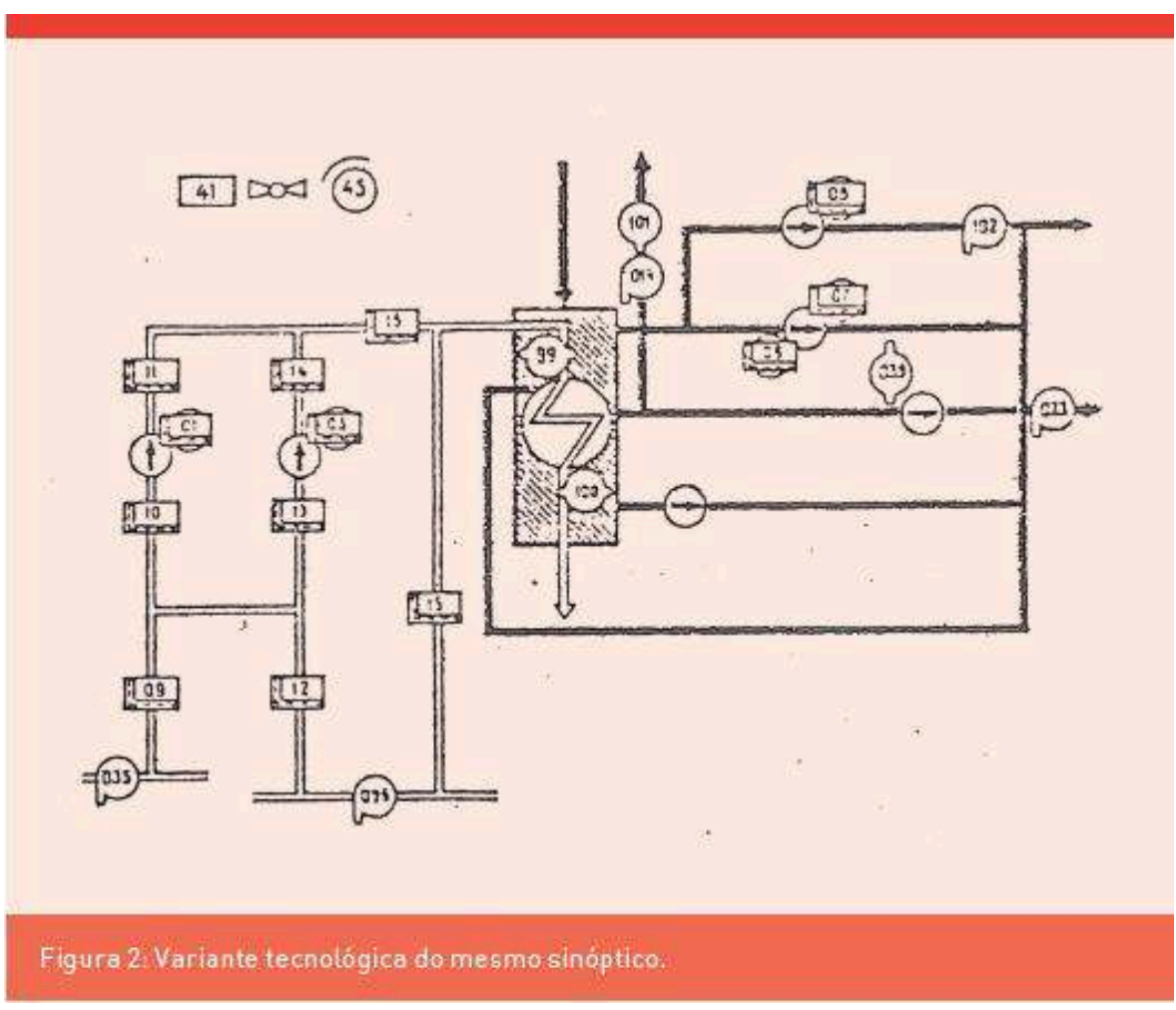

Comparemos la variante "psicológica" que establecimos para el sinóptico del circuito de aceite de una central térmica con el sinóptico "tecnológico" de este mismo circuito.

Lo que diferencia fundamentalmente nuestra sinóptica de la variante tecnológica es que está basada en el principio de integración y de diferenciación de la información/ imagen con la puesta en evidencia de las estructuras semánticas parciales que observamos en nuestros sujetos en el momento de la formación de la imagen operativa. En este caso concreto de esquema sinóptico ese principio encontró su manera de ser expresado:

a) en una nítida delimitación de la zona de señalización (instrumentos indicadores $073,039,045,101,014,102,99,100)$ y de la zona de mando (válvulas $09,10,11,12,13,14,15,18$ y bombas a motor 08, 06, 07, 01, 03) ;

b) en la conexión estructural de las salidas ("enlaces") del grupo electrógenos referentes a las correspondientes fuentes de información (tres rayos en la parte superior de nuestro esquema);

c) en el aislamiento estructural, en el interior de la zona de comando, y la organización en una línea inmediatamente visible de las bombas de agua y aceite que son los principales medios de acción en la dinámica de los fluidos tecnológicos $(08,07,01,03)$;

d) en la atribución, en la representación del grupo electrógenos, de una forma específica y llamativa que favorece la localización operativa de la información que se refiere a este, en la sinóptica general de la central, extremamente complicada y sobrecargada.

Extraído de [OSHANIN (1969)]. 
- Es completada por la acción. Por lo tanto constituye "una estructura informativa especializada (y no universal) que se forma en el transcurso de una u otra acción dirigida a los objetos", por oposición a la "imagen cognitiva" que sería "el reflejo integral de los objetos en la diversidad de sus propiedades accesibles".

- Es selectiva y lacónica. Solo retiene lo que tienen valor para la acción y suprime el "ruido" informativo. "Un espectador no es un hombre de acción" decía OSHANIN, "hay demasiada información". Se trata de otra diferencia de imagen cognitiva: "el valor de la imagen cognitiva consiste en ser lo más completa posible, el valor de la imagen operativa es el de ser la menos obstructiva (...) Todo deber ser "económico" : en relación a la plétora de la imagen cognitiva, la imagen operativa es lacónica" [OSHANIN (1969)]. Cuanto más rápida sea la respuesta más acentuado será el laconismo de la información retenida.

- Está sujeta a la "deformación funcional". "La imagen es una réplica deformada del objeto", dado que la imagen operativa presenta una "acentuación de los puntos de información más importantes en función de la tarea enfrentada" [OSHANIN (1972)]. La deformación no implica error, sino una jerarquización particular de los elementos de la realidad pertinentes para el operador, que puede parecer una "monstruosidad tecnológica" pero es eficaz. De este modo la deformación incide tanto en los datos como en las relaciones entre ellos, lo que demuestran los estudios sobre los "mapas mentales": por ejemplo los trayectos de los peatones evaluados, no por el número de pasos, sino por las actividades que realizan a lo largo del trayecto [WEILL-FASSINA (1981)], o las diferentes representaciones de los choferes de taxi en función de si las zonas pertenecen a la "red básica" o a la "red secundaria" que se construyeron con la experiencia [PAILHOUS (1970)].

Las implicaciones de la noción de la imagen operativa

\section{- La construcción por la acción y el dinamismo de la imagen}

La imagen no es la "copia durmiente de experiencias anteriores " [NEISSER (1967)], se construye a partir de la exploración activa de la realidad, en función de las acciones sobre el objeto y de transformaciones del objeto consecutivas a la acción.

OSHANIN insiste en el carácter dinámico de la imagen operativa que es doble dado que el operador se transforma y que el sistema de trabajo se modifica constantemente. La imagen operativa refleja simultáneamente esta dinámica instantánea de la situación y la dinámica deseada (ella misma es la representación móvil de las transformaciones esperadas por el operador).

16

De este modo integra la formación anterior, la información previa ofrecida sobre el sistema, y la experiencia (acumulación del saber hacer). Por otra parte, la imagen operativa se empobrece, poco o nada, al ser utilizada en una acción que la reactualice. Es el problema que plantea el tratamiento de los incidentes raros.

- Las transformaciones de la imagen en función del objetivo que se quiere alcanzar mediante una misma tarea

17 Un mismo operador puede construir diversas imágenes operativas del mismo dispositivo según el objetivo que se propone o que le es impuesto en diferentes momentos. Pero la eficacia de estas imágenes no es equivalente en lo que respecta a la realización final. Una experiencia sobre el control de un proceso cíclico variable con detección de "incidentes" aleatorios muestra la superioridad de la instrucción "detener el proceso antes de que el incidente intervenga" sobre la instrucción "detener en cuanto surja 
el incidente", siendo diferentes las "imágenes operativas" y los indicadores utilizados en los dos casos [OSHANIN (1973)].

La mayor parte de las investigaciones de campo ergonómicas actuales confirman estos resultados: los operadores intentan detectar el incidente preferiblemente antes o a punto de producirse que después. Se desarrollan muchos indicadores de alerta formales e informales con el fin de anticipar el incidente. Es uno de los problemas ocasionados por las instalaciones informatizadas muy sofisticadas, y que no siempre permiten esta anticipación, lo que es muy costoso para los operadores (y probablemente para la seguridad del sistema).

- La imagen varía en función de la tarea que hay que cumplir y de la función que se cumple en la empresa.

19 Ya se comentó que el esquema "psicológico" de los operadores y el esquema tecnológico del diseñador o del ingeniero, no tienen nada que ver entre sí. Las diferentes tareas por realizar arrastran una cantidad heterogénea de representaciones del mismo dispositivo en el seno de los miembros de una empresa, ya sean operadores de control u operadores de exterior, ingenieros, personal de mantenimiento, constructores... Los trabajos de [RICHARD (1983)] mostraron recientemente que, en el ámbito de la informática, la lógica del funcionamiento (con orden $\mathrm{A}$--- efecto $\mathrm{B}$ ) difería de la lógica de utilización (si se desea efecto B --- orden A). Ninguna de las imágenes, ninguna de las lógicas es mejor que las otras, son fragmentarias y parciales y sobre todo complementarias ; y estas diferencias deben reconocerse y ser tomadas en cuenta en la empresa si se quieren evitar dificultades en la realización del trabajo o desajustes graves en las instalaciones.

- Los límites de la "imagen operativa" : la noción de "representación funcional"

20 A pesar de reconocer la riqueza y originalidad de la contribución de la noción de "imagen operativa" en el dominio de la psicología y la ergonomía, algunos psicólogos del trabajo propusieron, a principios de los 80 , utilizar de ahí en adelante, sobre todo el concepto de "representación funcional". Al mismo tiempo, al ser más preciso y más completo que la "imagen operativa", permite evitar los riesgos de confusiones semánticas y reintegrar el significado de la imagen para el operador, la posibilidad de realizar transformaciones de la imagen y de pasar de una imagen a otra [VERMERSCH (1981) ; WEILL-FASSINA (1981); LEPLAT (1985)]. Por ejemplo, la representación que se obtendrá de una ciudad constituirá primero una visión muy global, con algunas referencias. Seguidamente podrán establecerse itinerarios, tratándose ya de una representación estructurada de la ciudad. Después se analizarán (algunos) elementos y se transformará esa imagen, situándose en el interior, sobre diferentes puntos de vista, según lo que se tiene que hacer en la ciudad. Es así como se reintroduce la noción de "operaciones en la imagen".

\section{Algunas cuestiones planteadas actualmente a propósito de las representaciones}

21 . La variabilidad temporal de las representaciones. Desde hace varios años las investigaciones de cronología realizadas durante el trabajo ponen en evidencia las variantes importantes de los procedimientos de trabajo en función del momento de la jornada : variaciones ultradianas (<24) y circadianas (relacionadas con el nictímero). Por 
ejemplo, las modalidades de control visual de un cuadro de control son diferentes de día o de noche, y muestran diferencias en las representaciones del dispositivo de los mismos operadores en función de su estado interno, lo que tiene varias consecuencias a nivel organizativo del trabajo y de la concepción de los dispositivos técnicos [QUEINNEC et al. (1981)].

22 . Los "errores diabólicos" de representación. Aquí se trata de la problemática del "error humano", término que preferimos al de "fracaso", siguiendo la estela de [WISNER y DANIELLOU (1986)] que evita la polarización en un solo individuo. Sea como sea, los accidentes espectaculares de los últimos años, especialmente el de Three Mile Island, implicaban ese error de representación del sistema (la indicación de una orden "válvula cerrada" se tomó como la indicación de un resultado), y sobre todo, como ese tipo de error puede perseverar, se lo calificó como "diabólico" ("errare humanum est, perseverare diabolicum" [CARNINO et al. (1986)].

23 Según estos autores, ese tipo de error puede posicionarse a nivel de los mecanismos y de las disfunciones internas del razonamiento del individuo, o al nivel de una interpretación inicial inexacta a pesar de que los razonamientos ulteriores fuesen coherentes. La cuestión es, entre otras, la capacidad o incapacidad de los operadores para movilizar instantáneamente, en el momento preciso, las representaciones mas operacionales para enfrentar el incidente y los factores que bloqueaban esa capacidad de movilización, aunque dispongan de conocimientos suficientes para desempeñar la tarea (en relación a lo que se dice en el punto anterior, es necesario tener en cuenta que las grandes catástrofes tuvieron lugar, en su gran mayoría, a primera hora de la mañana (alrededor de las 4 h00 AM, el momento del punto más bajo de la vigilia de funcionamiento de organismo humano).

24 . Los modos de construcción de las representaciones. Se plantean varias cuestiones: ¿Cómo se elaboran las representaciones? ¿Cuál es la articulación entre la formación inicial y la experiencia? ¿Qué herramientas formales son útiles, o al contrario, cómo se compensa la ausencia de herramientas formales y cuáles son las consecuencias de la acción?

25 . Las representaciones colectivas. Un gran número de cuestiones constituyen el objetivo de las investigaciones en este ámbito [SAVOYANT (1981)] : las modalidades de construcción de representaciones colectivas. ¿Cómo se utilizan? ¿Qué comunicaciones exigen? ¿Qué modo de confrontación?

26 . El acceso a las representaciones. Este punto en particular requeriría todo un artículo, dado que plantea la cuestión de los métodos que puede utilizar un analista que retiene su propia representación de la de otros : observación de los procedimientos, verbalizaciones provocadas o no, inmediatas o diferidas, análisis de los productos de la actividad (notas, esquemas, diseños personales, "características" diversas...). Parte de las contribuciones de este volumen abordan esta cuestión que aquí no desarrollaremos.

27 . Representación funcional/representación psicoafectiva. Un último punto, que simplemente mencionaremos, es el de la articulación entre la representación funcional ligada a la ejecución práctica del trabajo y la representación psicoafectiva que el operador construye de su propia relación con el trabajo. Constituye, entre otros, el objeto de un seminario interdisciplinar cuyos trabajos fueron publicados [DEJOURS et al. (1988)]. 


\section{Algunos campos de aplicación de las "representaciones funcionales"}

- La concepción de nuevos dispositivos. Para concebir eficazmente nuevos dispositivos técnicos es indispensable, entre otras cosas, poder prever cuándo se realizará "la actividad futura posible" de los operadores que los deberán utilizar. Por este motivo, es útil y necesario confrontar el conjunto de las diferentes representaciones de todos los integrantes de la empresa (operarios, técnicos, desarrolladores) y las de los ergónomos, con el fin de conseguir la formulación de propuestas eficaces desde el punto de vista del funcionamiento de las instalaciones y el respeto de los modos de funcionamiento humano [DANIELLOU (1985)].

Además de esto, la elaboración de diversas "ayudas al trabajo" debe basarse en el análisis de las representaciones de los usuarios, en caso contrario podría ser inútil o incómodo en la realización del trabajo [WEILL-FASSINA (1981)].

. La formación de los operadores. En este dominio, las "representaciones funcionales" de los operadores forman la base a partir de la cual la formación puede, o debe, construirse. Un operador en formación no es una cabeza vacía que hay que rellenar, menos aún cuando ya tiene cierta edad y por lo tanto, cierta experiencia, aunque sea limitada. El conocimiento de estas "representaciones" es una etapa previa a cualquier transmisión de nuevas informaciones y una condición de su asimilación.

\section{Conclusión}

Para terminar, muy brevemente, citaré a [LEPLAT (1985)] quien plantea cuestiones tales como "¿qué sería necesario sustituir al concepto de representación mental para poder excluirlo, y así comprender su importancia ?".

\section{BIBLIOGRAFÍA}

Bainbridge, L. (1969). The nature of mental model in process control. Unpublished paper. Dept. of Psychology. Univ. of Reading. England.

Bisseret, A. (1970-1971). Mémoire opérationnelle et structure du travail. Bulletin de Psychologie, XXIV, 5-6, N 289, 280-294.

Carnino, A. et al. (1986). Les erreurs de représentation : pourquoi certaines peuvent être qualifiées de "diaboliques". Rapport GRETS-EDF, Paris.

Daniellou, F. (1985). La modélisation ergonomique de l'activité de travail dans la conception industrielle. Le cas des industries de processus continu. Thèse pour le Doctorat d'ergonomie. CNAM, Paris. 
Dejours, C. et al. (1988). Plaisir et souffrance dans le travail. Orsay, Éditions de l'AOCIP.

Leplat, J. (1985). Les représentations fonctionnelles dans le travail. In S.Ehrlich, Les représentations. Psychologie Française. Paris : A. Colin.

Neisser, U. (1967). Cognitive psychology. New York: Appleton-Century-Crofts.

Ochanine, D. (1969). Rôle de l'image opérative dans la saisie du contenu informationnel des signaux. Questions de psychologie, $\mathrm{n}^{\circ} 4$.

Ochanine, D. (1972). Déformation fonctionnelle des images opératives . Questions de psychologie, $\mathrm{n}^{\circ} 4$.

Ochanine, D. (1977). L’image opérative. Séminaire du Laboratoire de physiologie du travail Ergonomie, CNAM (non publié).

Pailhous, J. (1970). La représentation de l'espace urbain. L'exemple du chauffeur de taxi. Paris : PUF.

Piaget, J., \& Inhelder, B. (1966). L'image mentale chez l'enfant. Paris, PUF.

Richard, J-F. (1983). Logique de fonctionnement, logique d'utilisation. Rapport INRIA, n 202, 47.

Savoyant, A. (1981). Image opérative et problèmes de coordination inter individuelle dans l'activité collective. In L'image opérative . Actes du séminaire du Département d'ergonomie et d'écologie humaine. Université Paris I. 82-90.

Vermersch, P. (1981). Image opérative ou représentation fonctionnelle ? A propos de quelques difficultés sémantiques. L'image opérative. Actes du séminaire du Département d'ergonomie et d'écologie humaine. Université Paris I, 44-60.

Weill-Fassina, A. (1981). Image opérative ou représentation fonctionnelles ? Intérêt pour la conception et l'utilisation d'intermédiaires graphiques. L'image opérative. Actes du séminaire du Département d'ergonomie et d'écologie humaine. Université Paris I, 61-81.

Wisner, A., \& Daniellou, F. (1986). Vers une technologie "Cerveau compatible". Actes du premier Congrès international sur le génie industriel AFCET-CEFI- XGi, 791-799. 